\section{Escritura en migración: transmedialidad y poética en Cristina Rivera Garza \\ Andrés Olaizola ${ }^{(1)}$}

Resumen: En artículos incluidos en sendos volúmenes anteriores (El camino de la heroína, el arquetipo femenino universal para un nuevo paradigma y El camino de la heroína, narrativa, género y diversidad) hemos avanzado en la identificación de las estrategias transmediales en un corpus de textos de la escritora mexicana Cristina Rivera Garza. El presente artículo continúa con dicho eje de investigación y lo profundiza, para reflexionar de qué manera la transmedialidad forma parte de la poética de Rivera Garza, o mejor dicho, cómo las derivas transmediales ejecutan, pero a la vez posibilitan, las trayectorias a través de los géneros, medios y lenguajes que la escritora mexicana postula en los textos ensayísticos impresos y digitales que desarrollan sus planteos estéticos y poéticos.

La propia Rivera Garza ha definido a su escritura como en suspenso constante, irresoluta entre géneros. Para la escritora mexicana, la escritura es una práctica, un trabajo con el lenguaje en y a partir del movimiento: cuando se escribe, lo fisiológico se transforma, lo psicológico se transforma. "Escribir es el acto físico de pensar" (Rivera Garza, 2007, p. 13): el cuerpo y la mente en movimiento en y por la escritura, que reproduce esa misma errancia, ese devenir en y a través las lenguas, los lenguajes, los textos, los géneros y los medios.

Palabras clave: Transmedialidad - Transficcionalidad - Escritura en migración - Escrituras digitales - Escrituras colindantes - Blogs - Poéticas - Rivera Garza - Literatura latinoamericana del siglo XXI - Literatura mexicana del siglo XXI.

[Resúmenes en inglés y portugués en las páginas 152-153]

${ }^{(1)}$ Andrés Olaizola es Licenciado en Letras (UBA), Profesor Universitario en Letras (UP), Magíster en Educación Superior (UP). Becario doctoral del CONICET. Adscripto al Instituto de Literatura Hispanoamericana (FFyL, UBA) y a la cátedra Problemas de Literatura Latinoamericana "B" (FFyL, UBA). Su tema de investigación son las estrategias transmediales en un corpus de textos de la escritora mexicana Cristina Rivera Garza. Fue docenteinvestigador de la Facultad de Diseño y Comunicación de la Universidad de Palermo. aolaizola@gmail.com 


\section{Introducción}

En artículos incluidos en sendos volúmenes anteriores (El camino de la heroína, el arquetipo femenino universal para un nuevo paradigma y El camino de la heroína, narrativa, género y diversidad), explicamos que, en los últimos años, cada vez más proyectos, objetos, programas, artefactos, obras, textos pertenecientes a las esferas artística y cultural poseen, en alguna o en todas las etapas del proceso productivo, algún componente transmedial. En lo que respecta a la industria audiovisual, por ejemplo, "transmedia" se ha convertido en la "palabra mágica" de cualquier proyecto de media o gran envergadura; de hecho, "en algunos momentos parece como si ya no se pudiese hacer algo que se desarrolle en un único medio" (Tubau, 2011).

A diferencia de la esfera audiovisual, en donde lo transmedial se constituye como una posibilidad bastante certera de acrecentar las ganancias de los proyectos, en la esfera de la literatura impresa, la transmedialidad es una decisión que depende más de los/as escritores/as y artistas que de los/as editores/as. La mayoría de los grandes conglomerados editoriales no suelen apostar en proyectos transmediales, ya que eso aumentaría los costos de cada lanzamiento ${ }^{1}$. Por lo tanto, son las editoriales pequeñas, alternativas y/o gubernamentales las que aceptan y llevan adelante la mayoría de los proyectos transmediales de origen literario. Repasemos a continuación algunos ejemplos transmediales en el sistema literario latinoamericano contemporáneo.

La novela Keres cojer? = guan tu fak (2005, Interzona), de Alejandro López, cuenta con unos videos que imitan el formato de los programas periodísticos de investigación y que se relacionan con la trama. Durante un tiempo, los videos estuvieron alojados en el sitio Web de la editorial Interzona, y hoy se pueden encontrar en YouTube 2 . El medio foráneo "se entiende como generador de verosimilitud para la ficción" (Schmitter, 2019, p. 57).

Reinaldo Laddaga ejercita de curador de Cosas que un mutante debe saber (2013, Unsounds), un libro-objeto que, a través de 55 relatos acompañados de ilustraciones y 55 piezas sonoras, oficia de suerte de continuación de Cuentos breves y extraordinarios (1956), de Jorge Luis Borges y Adolfo Bioy Casares

Cada uno de los poemas de Primera línea de fuego (2013, Tenemos las máquinas), de Tálata Rodríguez, posee un código QR que, al escanearlo, direcciona a un video en donde la poeta recita el texto en lugares como el subterráneo, un taller mecánico o el estadio de Boca Juniors. De esta manera, se articulan dos dispositivos poéticos: "la poesía, fijada por el texto, publicada como libro [...] y el clip de poesía que combina en una expresión poética el contenido, la voz, el ritmo, la imagen y la duración" (Schmitter, 2019, pp. 56-57). 80 días (2014, Alquimia Editorial), de Jaime Pinos, con fotografías de Alexis Díaz, posee una página Web en donde, además de los textos y las fotografías, hay una "escenografía sonora", tal como la denomina su compositor, Carlos Silva (Schmitter, 2019, p. 57).

Diario de un bebedor de petróleo (2015, Ediciones Vox), de Juan José Mendoza, es un poemario que viene acompañado por un CD llamado DBP, en el cual el músico experimental Alan Courtis realiza un tratamiento sonoro de varios poemas leídos por el propio Mendoza. El poemario Metadrones (2015, Centro de Cultura Digital), de Horacio Warpola, posee dos ediciones digitales: una en formato ePub, el cual tiene gifs elaborados por Canek Zapata; y otra edición en formato pdf, en donde dichas animaciones se transforman en 
ilustraciones fijas. La edición en pdf no dista mucho de ser un poemario digitalizado con imágenes; en cambio, en el ePub, cada texto está articulado junto a un GIF "que lo intercepta visualmente y que obliga a una lectura interactiva, ya que es necesario cliquear en la imagen para leer el poema" (Sánchez-Aparicio, 2019, p. 5).

Estas contadas marcas en el mapa de los textos literarios impresos latinoamericanos que entienden a la transmedialidad como parte de su estética evidencia que la producción de Cristina Rivera Garza no es una rara avis en este contexto, y que las conclusiones que ensayemos en este trabajo bien puedan servir para reflexionar sobre un panorama mucho más general. Sin embargo, es necesario también indicar que las estrategias transmediales que despliega Rivera Garza se llevan adelante en y a través de textos publicados tanto por editoriales independientes (Práctica mortal, Bonobos Editores) como por grandes editoriales (Random House, Fondo de Cultura Económica).

\section{Sobre la transmedialidad}

Si bien es posible rastrear el concepto de transmedia hasta 1975 en el ámbito de la música (Porto \& Flores, 2012), Marsha Kinder (1991) lo emplea por primera vez en el campo de las Ciencias de Comunicación. Luego, Henry Jenkins $(2003,2006)$ lo reformula en el concepto de narrativa transmedia, el cual queda vinculado, sobre todo, al ámbito de la industria del cine, la televisión y los videojuegos. A partir de los trabajos de Jenkins, la transmedialidad adquiere gran centralidad en el campo de las Ciencias de la Comunicación y del Diseño Audiovisual, importancia que queda consolidada, sobre todo en el ámbito hispánico, con las investigaciones de Carlos Scolari $(2008,2013)$.

En nuestro trabajo, tomamos el análisis que realiza Claudia Kozak (2015), porque evita centrarse exclusivamente en el ámbito de la industria audiovisual y ofrece una definición amplia de lo transmedial. Kozak repasa las diversas genealogías y usos de la noción. Para comenzar el recorrido, explica que lo transmedial hace referencia "a algún tipo de transferencia de elementos entre un medio y otro sin que cada uno de ellos pierda su especificidad; desde esa perspectiva se analiza por ejemplo cómo un mismo tópico, estética, discurso aparece en medios diversos" (p. 256).

Sobre la base de la primera definición que revisa Kozak, cuya generalidad y síntesis permite ser aplicada en diferentes áreas de la esfera artística y cultural, podemos avanzar hacia una conceptualización de la transmedialidad más específica al sistema literario. En este marco, podemos destacar a Ryan (2013), quien emplea los conceptos narratológicos de "mundo de la historia" (storyworld) y transficcionalidad para definir a la narrativa transmedia.

El "mundo de la historia" es una representación mental que se construye durante la lectura/visionado con los textos narrativos. Modelo dinámico de situaciones en continua evolución, el "mundo de la historia" está compuesto por los siguientes componentes: las y los existentes (especies, instituciones sociales, objetos, personajes que habitan en el mundo); un folklore que se relaciona con las y los existentes; un espacio con determinados rasgos topográficos; leyes naturales, leyes sociales y valores; eventos físicos que ocasionan cambios en las y los existentes; y eventos mentales que le brindan significado a los eventos 
físicos, afectan las relaciones entre los personajes y ocasionalmente alteran el orden social (Ryan, 2013, pp. 364-365).

El "mundo de la historia" puede establecer diferentes relaciones con los textos: textos con un único mundo de la historia, textos con múltiples mundos de la historia, y un mundo de la historia que se desarrolla a lo largo de diferentes textos (Ryan, 2014). Dos conceptos centrales para entender esta última relación son la transficcionalidad y la transmedialidad. La transficcionalidad es la relación que se establece cuando dos o más textos comparten personajes, lugares imaginarios, mundos ficcionales, etc. (Saint-Gelais, 2005, p. 612). Si bien la transficcionalidad puede ser entendida como un tipo particular de hipertextualidad, una de las formas de la transtextualidad ya delimitadas por Gerard Genette en 1962, este concepto adquiere nuevas implicancias cuando esa migración de entidades ficcionales puede darse entre textos de diferentes medios. La transficcionalidad como fenómeno literario emerge a partir de la era de la imprenta, florece con la era electrónica (radio, televisión, cine) y adquiere nuevas formas a partir de la era digital (Ryan, 2008). A partir de estas consideraciones, Ryan (2013) sostiene que la transficcionalidad que opera en diferentes medios, tanto analógicos como digitales, se entiende como transmedialidad.

Antes de seguir avanzando, cabe hacer una aclaración. En este breve marco teórico hemos partido de una definición bastante general de transmedialidad, lo cual nos permitió detallar un uso más literario del concepto. Sin embargo, en este punto ha surgido el término narrativa transmedial o transmedia, que inevitablemente se contrapone con el hecho de que en el corpus de textos de Rivera Garza que vamos a analizar hay algunos que se alejan de lo narrativo y se vinculan más con lo ensayístico y lo lírico.

La propia Rivera Garza ha definido a su escritura como en suspenso constante, irresoluta entre géneros (Wolfenzon, 2015, p. 25), con lo cual bien podríamos hacer un atajo crítico y sostener que, en tanto la práctica escritural de Rivera Garza se posiciona en un pliegue entre géneros, las conclusiones que se derivan del concepto de narrativa transmedia son factibles de extrapolarse a textos como los poemarios Los textos del yo (2005) o La imaginación pública (2015). Sin embargo, es posible ofrecer otra lectura, la que no solo complejiza el concepto de transmedialidad, sino que propicia una herramienta teórica para similares proyectos transmedia de origen literario, que como hemos visto son más que usuales. $\mathrm{Al}$ revisar el concepto de "mundo de la historia", Frank Zipfel (2014) explica que no todos los mundos ficcionales son mundos de la historia, por lo tanto puede haber textos ficcionales sin historia; ejemplo de ello puede ser un texto que solo consista en una descripción de un objeto no real (p. 111). Si aceptamos que Zipfel establece que hay formas no narrativas de la ficcionalidad, podemos sostener que también que la transficcionalidad y la transmedialidad no son exclusivamente narrativas.

Jan-Noël Thon (2016) parte de una noción amplia del concepto (al que entiende como los fenómenos que se manifiestan a través de distintos medios), para luego indicar que la transmedialidad posee una "cualidad de significación cultural" que privilegia estrategias de representación en lugar de lo que estas estrategias representan, pero que también puede ser observada al nivel de "dispositivos formales ahistóricos" que ocurren un más de un medio, como la repetición de motivos, la variación temática y la narratividad (pp. 11-13). Thon luego detalla que su trabajo analizará las estrategias transmediales de representación narrativa y su realización 
dentro de la medialidad específica de películas, historietas y videojuegos. La aclaración no nos resulta nimia, más si tomamos en consideración la concepción escalar de la narratividad que postula Ryan $(2006,2007)$, en tanto que permite entender que las estrategias transmediales de representación pueden representar a través de varios medios un mundo de la historia (nivel alto de narratividad), o solo representar, por ejemplo, un motivo, una estética, un discurso (bajo o nulo grado de narratividad), con distintos niveles intermedios.

\section{Transmedialidad y poética}

Es importante señalar que el análisis de los vínculos entre los textos de Rivera Garza como estrategias transmediales es una perspectiva de lectura prácticamente sin antecedentes. Ninguno de los artículos compilados en cualquiera de las tres antologías críticas sobre Rivera Garza (Cruz Arzabal, 2019; Estrada, 2010; Palma Castro et al., 2015) emplea el concepto de transmedialidad. De hecho, los trabajos sobre el blog personal de Rivera Garza (No hay tal lugar. U-tópicos contemporáneos) son solo cinco (Choi, 2006, 2007, 2010; Griboul, 2006; Keizman, 2013) y los ensayos sobre las producciones multimodales son cuatro (Bautista Botello \& Pérez López, 2018; Cruz Arzabal, 2014, 2016; Sánchez-Aparicio, 2018). Merecen destacarse los artículos de Vega Sánchez-Aparicio $(2014,2018)$, para quien la transmedialidad sí es una variable que entra en juego en la producción de Rivera Garza.

En anteriores trabajos, hemos avanzado en la identificación de las estrategias transmediales en un corpus de textos de Rivera Garza. El objetivo del presente texto, más allá de trazar las relaciones entre los textos analizados, es reflexionar de qué manera la transmedialidad forma parte de la poética de Rivera Garza, o mejor dicho, cómo las derivas transmediales ejecutan, pero a la vez posibilitan, las trayectorias a través de los géneros, medios y lenguajes que la escritora mexicana postula en textos ensayísticos en donde desarrolla sus planteos estéticos y poéticos.

Antes de adentrarnos en las descripciones de las estrategias transmediales en los textos de Rivera Garza, debemos hacer una breve digresión teórica. Ryan (2008, 2013, 2017), a partir de la relación entre mundos ficcionales (y la relación entre los textos que los crean) que describe Lubomír Doležel en Heterocósmica: ficción y mundos posibles, explica que la transficcionalidad (y la transmedialidad como uno de sus tipos específicos) se basa en tres operaciones: expansión, modificación y transposición.

La relación de expansión consiste en extender los límites, la dimensión del mundo original agregando más existentes, a través de una serie de operaciones: transformar a personajes secundarios en protagonistas de la historia, hacer que personajes visiten nuevas regiones del mundo, y prolongar la línea de tiempo de la historia original por medio de secuelas y precuelas.

Scolari (2009) identifica tres tipos de expansiones: historias intersticiales, que se desarrollan antes (precuelas), después (secuelas) o entre los textos/documentos que representan la macrohistoria y con la cual poseen una relación muy cercana; historias paralelas, que se desarrollan al mismo tiempo que la macrohistoria y que pueden evolucionar para transformarse en spin-offs; e historias periféricas, que pueden ser consideradas satélites más o 
menos distantes de la macrohistoria", con la cual poseen una relación débil. Ryan (2013) sostiene que las historias periféricas son muchas veces "leyendas" que se relacionan con los objetos o las y los existentes del "mundo de la historia" (p. 369).

La relación de modificación construye versiones diferentes del mundo, rediseñando su estructura y reinventando su historia. La modificación, de acuerdo con Ryan (2013), no es tan común en los proyectos transmediales, porque amenaza la integridad del "mundo de la historia" original.

La transposición es la relación que conserva el mismo argumento del mundo, pero lo transporta a diferentes locaciones temporales o espaciales. Tanto la modificación como la transposición se refieren a mundos que están relacionados con el original, pero que en definitiva son diferentes.

Tal como explicamos anteriormente (Olaizola, 2019, 2020), la novela La muerte me da (2007) se publica en simultáneo con el poemario La muerte de da (2007), cuya autora es Anne-Marie Bianco, uno de los personajes de la novela. La Detective, una de las protagonistas de La muerte me da, aparecerá de nuevo en los cuentos de La frontera más distante (2008), en la serie del blog Las Afueras (2008-2011)3 y en la novela El mal de la taiga (2012). El personaje de Grildrig es la protagonista de dos "temporadas" de la fotonovela Las aventuras de la Increíblemente Pequeña (2010-2011), de la serie de seis "telegramas" publicados en el blog ${ }^{4}$, y finalmente vuelve a aparecer en un capítulo de Había mucha neblina o humo o no sé qué (2016).

Este "mundo de la historia" se extiende a lo largo de nueve años y conforma un sistema transmedial, ya que se vincula con textos de diferentes medios (narrativa impresa, narrativa visual y verbal digital, lírica impresa) y transficcional, en tanto establece relaciones con textos de un mismo medio (publicaciones en el blog).

Por último, en un planteamiento teórico que consideramos logra conjugar ciertos aspectos de las "poéticas tecnológicas" y de la transmedialidad, Gianna Schmitter (2019) elabora el concepto de "transliteraturas", el cual puede ser apropiado para describir algunas directrices de la poética de Rivera Garza. De acuerdo con Schmitter, las literaturas hispanoamericanas de lo ultracontemporáneo (Schmitter, 2018a), de forma cada vez más frecuente, hacen uso de estrategias "trans", es decir, que "traspasan constantemente fronteras y se sitúan en una zona intersticial entre dos o más regímenes estéticos, materiales, nacionales y/o institucionales" (p. 54).

Para pensar estas producciones literarias, Schmitter propone el término "transliteraturas", que se caracterizarían por tematizar la transición y la crisis (histórica, política, económica, corporal, etc.); estarían pobladas de personajes trans (tránsfugas, nómades, híbridos, monstruos, transgéneros, personajes en transición constante, etc.); ejecutarían procedimientos metaliterarios que tematizan la transición y la crisis de la literatura; se presentarían como transnacionales (más allá de lo nacional, de la tradición, de un monolingüismo, etc.); entenderían a lo comunitario a través de colectivos de autores/productores, grupos de lectores, y estrategias como la co-escritura/reescritura/escritura no-creativa donde los lectores se vuelven autores-lectores-editores; y que se desbordarían siendo transgenéricas y transmediales, expandiéndose más allá de las normas, del canon, de los géneros, del objeto libro, etc. Tal como lo mencionamos en la introducción, la transmedialidad se ha constituido como una variable central en las esferas artística y cultural. Ante la avasallante retórica mercanti- 
lista y consumista de la industria audiovisual sobre la transmedia, que de forma aguda caracteriza Ryan (2016) a partir de un análisis sobre manuales escritos por profesionales del medio cinematográfico, pareciera que no hay espacio para entender a la transmedialidad como un procedimiento estético. Sin embargo, Vega Sánchez-Aparicio (2018), específicamente analizando las "poéticas disruptivas" de Rivera Garza, plantea que "si se entiende el fenómeno transmedia más como poética que como una estrategia de impacto en las audiencias, es posible separarlo de los intereses del mercado y de la absorción por parte de la industria" (p. 221). De hecho, Sánchez-Aparicio considera que el poemario La muerte me da es el punto de entrada a todo el sistema transmedia descripto, lo que implica un reto estético y "un desajuste en los objetivos de rentabilidad del proyecto" (p. 223). En tanto se desvincula de "las exigencias del consumo de la industria literaria, el mundo narrativo de La muerte me da no está sometido a los estándares de producción por los que se ven afectadas las creaciones transmedia más representativas" (p. 223).

En este trabajo, coincidimos con el planteo de Sánchez-Aparicio (2018) y sostenemos que la transmedialidad es un procedimiento que acciona las trayectorias mediáticas, genéricas y textuales que postula la poética de Rivera Garza como uno de los rasgos distintivos de su práctica escritural. Por ello, analizaremos distintos textos ensayísticos en donde Rivera Garza reflexiona sobre su propia escritura para exponer que el uso que la escritora mexicana hace de la transmedialidad no responde a una "moda" o a una estrategia de marketing, sino que es la puesta en texto(s), la ejecución y el movimiento mismo que tracciona su práctica constante de producir lenguaje (crg, 2007b).

En La muerte me da (2007), ante un poema escrito cerca del cuerpo de una víctima, la Detective dice que el "campo de acción" de la asesina es la poesía. Cécile Quintana (2016) toma esta frase para elaborar el planteo de que la producción de Rivera Garza debe entenderse como un "campo de acción" antes que un producto terminado.

Au-delà de son caractère transgénérique (poésie, nouvelles, romans, récits, essais), interdisciplinaire (histoire, littérature, sociologie) et, à l'occasion, bilingue (espagnol, anglais), son œuvre présente une cohésion artistique à travers le seul geste qui en stimule la création et constitue l'objet continu de sa réflexion: l'écriture.

La escritura cohesiona y (se) mueve (en) el campo de acción que constituye la producción literaria de Rivera Garza. Para Quintana, los textos de Rivera Garza reflejan el gesto de escribir, con lo cual surge en y a través de ellos la idea de movimiento. A partir de esta consideración, Quintana se basa en la "imagen-movimiento" de Gilles Deleuze (1983) para formular el concepto de "escritura-movimiento" como eje de la poética de Rivera Garza. Para Rivera Garza (2006), la escritura es una práctica, un trabajo con el lenguaje en y a partir del movimiento: cuando se escribe, lo fisiológico se transforma, lo psicológico se transforma. "Escribir es el acto físico de pensar" (Rivera Garza, 2007): el cuerpo y la mente en movimiento en y por la escritura, que reproduce esa misma errancia, ese devenir en y a través las lenguas, los textos, los géneros y los medios. La escritura es en/un acto de experimentación permanente "a través del cual, explorándolos, se tensan y, a veces, se desbocan, los límites del lenguaje” (Rivera Garza, 2007, p. 15). 


\section{Transmedialidad y traducción}

Betina Keizman (2020), a partir de la lectura de Gustavo Guerrero (2018), postula "el prototipo del escritor nómade" como modelo de escritor/a latinoamericano/a de fines del siglo XX, que participa activamente en la nueva ecología mediática, comunicacional y tecnológica, dinámica que se acentuará durante el siglo XXI. Los/as escritores/as nómadas son realistas "de nuevo cuño" ${ }^{5}$ que dan "testimonio de lo que ya está ocurriendo en el presente en que escriben" y cuyos textos se transforman continuamente "en piezas teatrales, o en instalaciones, o en videos, o en obra conceptuales" (Guerrero, 2018, p. 166). Para Keizman (2020), Cristina Rivera Garza "modula justamente este carácter nómade y propone, en su lugar, un estado migrante, avanzando un desprendimiento del implícito campo cultural que, aunque transformado, todavía presupone el análisis de Guerrero" (p. 199).

El estado migrante que propondría Rivera Garza, entonces, es articulado, accionado por la idea de la escritura en movimiento, en proceso de ser escritura permanente en y a través de cualquier espacio medial, textual o genérico. Esta dinámica que asume la escritura se entiende, porque ya desde su primer poemario, Los textos del yo (2005), leemos que no hay más espacio que el lenguaje: "Aquí, en el lenguaje, el único lugar." (Rivera Garza, 2014, p. 91). El lenguaje es lo único constante, es atravesado por todo lo demás: seguir al lenguaje en deambulatoria por territorios, pasando fronteras, y en ese mismo devenir configurar la poética del movimiento mismo, de las trayectorias. Serán las estrategias transmediales las que (se) ejecutan (en) la poética de Rivera Garza.

El concepto de "escrituras colindantes" de Rivera Garza es clave para entender por qué la transmedialidad puede asumirse como un procedimiento desarrollado en la práctica escritural de la escritora mexicana. En el artículo del volumen anterior, hemos explicado sus aspectos centrales, por lo tanto, para no ser reiterativos, diremos solamente que la idea de la colindancia permite entender que lo digital y lo impreso, los textos de un mismo medio y los de diferentes, así como la prosa y el verso, trazan trayectorias entre sí para conformar un objeto estético nuevo, basado en lo discordante, en lo incompatible, en la irresolución. Por otro lado, la transmedialidad se basa en el pasaje de un elemento de un medio a otro, lo cual implica un proceso de transposición, ya que el tema, estética, relato, discurso, personaje, mundo, entre otros aspectos, debe traducirse a otro lenguaje, a otro modo de composición. De hecho, es esperable que cada medio desarrolle sus potencialidades comunicativas y estéticas y que conserve su especificidad.

La traducción es un aspecto nodal en la poética de Rivera Garza, a tal punto que escribir y traducir son dos verbos que pueden constituirse en un solo concepto: "Utilizar recursos y retóricas propias de una lengua y aplicarlas a otra, descontextualizándolas, de alguna manera extrañándolas la una de la otra, eso es escribir en-traducción” (Rivera Garza, 2006, p. 81). Porque Rivera Garza no circunscribe la traducción a solo un pasaje de una lengua a la otra: "Escribir es traducir. El libro que se hace hoy mismo, en algún lugar de la Pantalla Cuyo Nombre, es un libro escrito directamente en traducción. Hay alguien, sin duda, que vive en Otro Lado y, utilizando incluso con palabras de su Propia Lengua, escribe en realidad en Otroladés" (crg, 2011).

A su vez, la traducción no solo se imbrica en la práctica escritural de Rivera Garza, sino también en su trayectoria profesional y vital. Tal como lo expone en Autobiografía del 
algodón (2020), la historia familiar y personal de Rivera Garza se organiza alrededor de la frontera de México con los Estados Unidos y, sobre todo, a partir del movimiento, de la migración: "Irse no fue una decisión sino una costumbre" (Rivera Garza, 2016). Y tal vez lo más destacable es que no entra en juego lo sedentario, sino que, así como su escritura, Rivera Garza se desplaza en el entre, en el pliegue de los espacios, porque para ella lo fronterizo es interesante en tanto "lugar umbroso, flexible, fluido, paradójico, donde confluye lo disímbolo" (Hong \& Macías Rodríguez, 2007).

La traducción, por lo tanto, es una condición de los sujetos y de los objetos (textuales): “Todo lo que es, es traducido". La traducción es un aspecto de la fenomenología de los seres y los textos, y podríamos agregar, de los espacios, ya sean físicos, virtuales, reales, ficcionales, etc.: "Más que una actividad, un estado del ser: traducir y ser traducido. Las dos cosas a la vez" (crg, 2007a).

Para Rivera Garza, "escribir es, sobre todo, escribir desde afuera de la lengua" (Rivera Garza, 2016): se escribe en tanto otros sujetos, porque la lengua es de la comunidad, por lo tanto, la escritura parte desde la comunidad para alejarse de ella, individualizarse por un instante, y después volver a la comunidad; como migrante se escribe en una lengua "sin Estado y sin ejército" (Rivera Garza, 2019, p. 173), en las afueras de la lengua del lugar hacia donde se emigró; como mujer, como disidencia, la escritura sale de los límites y coacciones de la heteronorma y del patriarcado. Se escribe en contra o afuera o en otro lado (Rivera Garza, 2016).

Lejos de pensar a la escritura como una práctica aislada, individual, todo texto que se produce, independientemente del lenguaje empleando (visual, verbal, audiovisual), es traducido, es una transposición de otro texto, de otro lenguaje, que ha sido producido y/o empleando por otros miembros de una comunidad. Leemos en una publicación del blog de Rivera Garza:

Lejos de la pureza del así llamado original, distanciada de la hermenéutica que busca un significado, de preferencia el único, detrás de los discursos o los objetos, la traducción es un recordatorio constante de nuestra condición alterada, es decir, de nuestra implicación incesante con el otro y la otra y los otros de esos otros (crg, 2007a).

La traducción, que es una de las formas que asume la escritura, implica el pasaje de límites, pero sobre todas las cosas, vincularse con otros/as. Ese movimiento hacia otros espacios, hacia otros sujetos necesariamente implica, de mínima, una interpelación, y de máxima, una transgresión y subversión. Para Rivera Garza, escribir (que también es traducir) puede entenderse como una línea de fuga: "No para entrar, sino para salir. Para cuestionar el estado de las cosas. Para hacerse preguntas imposibles. Para no tener nombre o para tener todos los nombres. Para todos los rostros. Para mutar. Para el plural. Hacia ti” (Rivera Garza, 2016).

La traducción es una manera de leer, de vivir, "más atenta". El acto de traducir es aproximarse, "volverse próximo y, por lo tanto, prójimo". La traducción, la transposición, lleva consigo el componente de la invención, del robo, de la traición, es cierto, pero también el de todos los agregados que realiza el/la traductor/a para convertirse en una corporalidad 
hacia el/la traducido/a. Rivera Garza explica que los dispositivos del poder llevan adelante una lectura en donde "soy una biografía compuesta de fechas límite y lugares inmóviles". Los datos consignados en los archivos institucionales, fechas y lugares, pretenden conformar un sujeto unívoco, con un solo género, profesión, espacio de origen y de fin. En contraposición, en la escritura hay un proceso constante de traducción, que produce sentidos y vínculos:

Cuando me traduzco para ti, soy estas palabras que me vuelven, acaso, inteligible. Tú. El que traduce atraviesa el puente y, justo en el centro, se avienta a las aguas que no cesan de pasar. El traducido emerge del agua, respiro atroz, para volver a sumergirse. Más que una actividad, un estado del ser: traducir y ser traducido. Las dos cosas a la vez. (crg, 2007a)

\section{Transmedialidad y deambulatoria (experimental)}

"El final es sólo una convención" (p. 40), postula Rivera Garza (2011b) en Viriditas, un libro con posteos aparecidos en el blog durante el 2010 y que se transponen para su publicación impresa un año después. Un corpus de textos originalmente digitales continúa produciendo sentido y adquiere nuevos significados cuando pasan a la esfera de la cultura impresa. "Todo final decepciona", propone Rivera Garza (cristina, 2003) en un temprano texto del blog, porque suele responder a motivos extra-textuales: "un contrato que se cumple, el aburrimiento del autor, las ganas de iniciar un nuevo libro, una fecha límite", etc. La transmedialidad evidencia que el final es "algo, de cualquier modo, prescindible" (crg, 2005).

A partir de una cita del escritor estadounidense Ron Silliman, Rivera Garza (2007) define a la narrativa como el desarrollo del significado a lo largo del tiempo, del espacio y del cuerpo (p. 15). Al conceptualizarla de esa manera, la narración adquiere como rasgo distintivo a la transmedialidad; incluso más, podría ser posible extender esta característica a la escritura misma.

En un artículo sobre su historia familiar de migraciones, Rivera Garza (2016) sostiene: "No creo en la escritura sedentaria. La escritura que me gusta denominar como verdadera es una escritura en migración". La condición de sujeto migrante se asimila al sujeto que escribe, porque la escritura es movimiento del cuerpo y se da en tanto un desplazamiento de tiempos y lugares: "Se escribe desde el fuera de lugar que es el lugar por excelencia del migrante".

El viaje, el pasaje de una instancia a otra, es un aspecto nodal de la biografía de Rivera Garza, pero es en sí la distancia producida por la partida lo que origina la práctica de escritura: "Se escribe en la distancia para vencer la distancia. Hay que estar ahí, rodeada de distancia, para creer lo imposible: que las palabras serán lo suficientemente poderosas para producir lo real" (Rivera Garza, 2016). Porque más que el momento exacto de irse, lo literario, lo estético se da en el entre, en el pasaje mismo de un lugar/texto/medio a otro: "de la frontera, lo que me resulta más interesante es el cruce -el cruce antes de que éste se 
transforme en una epopeya o una fuente de victimización” (Hong \& Macías Rodríguez, 2007).

Además de un proceso que puede pensarse como estético (porque está encarnado en la producción artística, pero también porque ilustra cómo Rivera Garza conceptualiza a la escritura), la deambulatoria, la movilidad intrínseca del ser humano, tal como explican Federici (2010) y Papadopoulos et al. (2008), es una forma de subversión y tiene tal potencial de motivar cambios sociales que origina dispositivos y formas político-culturales de control poblacional. Rebeldía y escritura se conjugan en las trayectorias del escritor mexicano José Revueltas y de la familia de Rivera Garza narradas en Autobiografía del algodón:

Somos trashumantes después de todo, andamos de un lado a otro como alma que lleva el diablo. Nos dejamos llevar, quiero decir. Nos gusta partir. Nos gusta producir la distancia donde después caben los recuerdos o la escritura. La melancolía. La rabia. Nos gusta desobedecer. Cuando hay un conflicto o la situación se vuelve insoportable, abrimos la puerta y dejamos todo atrás. (Rivera Garza, 2020, p. 296)

Así como los sujetos y las comunidades, la narración posee la propiedad de atravesar las fronteras temporales, espaciales y corporales, porque los pasajes, traducciones, expansiones y derivas están encarnados en la concepción de escritura de Rivera Garza. La transmedialidad es el procedimiento literario, artístico, que puede asumir los rasgos poéticos, estéticos, políticos de la deambulatoria. Para Rivera Garza (2011a), la primera y la última tentación son ciertamente narrativas (p. 35), entonces, se emplearán todas las estrategias transmediales para alcanzar esos deseos.

Un sistema transmedial que posee textos como las fotonovelas de Las aventuras de la Increíblemente Pequeña o los telegramas a las dos Pequeñas Forajidas en La imaginación pública, analizados en un anterior trabajo (Olaizola, 2020), podría ser catalogado como "experimental" y aducírsele que el mundo de la historia conformado carece de cohesión, dado que dichos documentos transmediales no son preponderantemente narrativos y se vinculan más al género lírico. Nada más alejado de la lectura que estamos proponiendo.

En Rivera Garza (2011a), el experimento, como estructura lúdica, no es la ausencia de la narración, es antes bien la posibilidad de cualquier tipo de narración en y a través de cualquier tipo de texto o medio: "La idea del experimento como juego [...] evita tanto la necesidad de percibir a lo experimental como opuesto al realismo narrativo" (p. 31). Como ya mencionamos más arriba, escribir, acto físico del pensar, "es una experimentación con los límites del lenguaje y, a final y principio de cuentas, un proceso de producción (de significados) (de realidad) (de mundos-otros)" (Rivera Garza, 2007, p. 13). Lo experimental, entonces, se entiende como constitutivo del acto de escribir en cualquier soporte, lo cual no invalida al realismo narrativo, antes bien, abre las puertas a otros tipos de realismos, a otras formas de la narrativa. La experimentación trabaja con lenguajes varios, con modos del relato, con las espacialidades y las temporalidades.

De la misma manera en que Manuel Puig demostró que "el interés narrativo no es contradictorio con las técnicas experimentales" (Piglia, 1993, p. 115), los procedimientos de composición más cercanos a lo experimental (escritura fragmentaria, escritura multimo- 
dal, no-linealidad, etc.) que se evidencian en la poética transmedial de Rivera Garza no solo responden a una tradición (a un relato) del experimentalismo literario que se remonta a principios y mediados de siglo XX en Europa, Estados Unidos y América Latina (Rivera Garza, 2004, p. 170), sino que dichos procesos serían perfectamente compatibles en la conformación de un "mundo de la historia", tal como se observa en el caso de La muerte me da y su expansión hacia otros textos y medios (Olaizola, 2019).

\section{Reflexiones finales}

Desde el inicio de la producción literaria de Rivera Garza, mucho antes de que ella introdujera la variable de lo digital, el eje de su poética es la "escritura en migración", la escritura en las trayectorias a través de fronteras genéricas, lingüísticas, corporales e identitarias. La inclusión de los entornos digitales a partir del año 2002 complejiza y pone en práctica las reflexiones sobre la propia poética. Desde entonces, la obra de Rivera Garza ha atravesado la problemática crítica entre tecnología y literatura. Pero aún más, y es aquí en donde Rivera Garza se diferencia de otros/as escritores/as en donde también se evidencian pasajes entre lo digital y lo impreso, sus últimos libros (Había mucha neblina o humo o no sé qué, publicado en el 2016, y Autobiografía del algodón, del 2020) incluyen en su dinámica y estructura los entornos digitales, pero los exceden, van más allá, planteando que la escritura es en tanto otras subjetividades, medios y espacios.

Rivera Garza (2013), parafraseando a Gertrude Stein, sostiene que la única obligación del escritor es producirse como contemporáneo de su época, por lo tanto debe, como vocación crítica más que como opción basada en el mero gusto personal, explorar las distintas formas de composición de un momento histórico (p. 208). Por lo tanto, la poética de Rivera Garza asume como un procedimiento lógico la transmedialidad, ya que sus potencialidades comunicativas y artísticas puede conjugar los rasgos poéticos, estéticos, políticos de la deambulatoria.

La transmedialidad ejecuta, pero a la vez posibilita, las trayectorias a través de los géneros, medios y lenguajes de la escritura en migración de Rivera Garza, aquella que traza derivas entre lo digital y lo impreso, entre las materialidades (de los textos, de las voces, de los cuerpos) y sus presencias y ausencias.

\section{Notas}

1. Además de la razón vinculada a los costos, otra posible razón puede hallarse en dos de las características del mercado editorial en la actualidad: la velocidad y la sobreproducción de libros que alcanza niveles de saturación (Guerrero, 2018). Estos rasgos distintivos se contraponen a lo que requieren los proyectos transmediales, basados en detalladas planificaciones, diseño de objetos y elementos con plazos extensos de ejecución, puesta en funcionamiento y desarrollo que siguen en gran medida los planes elaborados, y una 
persistencia y mantenimiento a lo largo del tiempo (Gallego Aguilar, 2011; Nallar, 2016; Tubau, 2011).

2. Schmitter (2019) explica que Alejandro López había planificado que la novela sea enteramente digital, a través de una página Web. Sin embargo, en un contexto post-crisis del 2001, Interzona rechazó el proyecto.

3. Publicaciones del 27 de febrero, 19 de marzo, 26 de marzo, 14 de abril, 16 de abril, 25 de abril, 17 de mayo, 20 de mayo, 28 de mayo, 29 de mayo, 12 de junio de 2008; publicaciones del 29 de enero, 16 de julio, 26 de julio, 7 de octubre y 3 de noviembre de 2009; publicación del 5 de febrero de 2010; publicación del 10 de enero del 2011.

4. "Me llamo cuerpo que no está: los enclíticos", última sección del poemario de Rivera Garza La imaginación pública (2015), engloba diecisiete textos, seis de los cuales son los “Telegramas para dos Increíblemente Pequeñas forajidas", mientras que otros siete son poemas que emplean la prosa de diferentes entregas de la fotonovela diurna y de otras publicaciones del blog No hay tal lugar.

5. En la llamada "trilogía Nocilla" de novelas, así como El hacedor (de Borges) remake, de Agustín Fernández Mallo, lo tecnológico se entrecruza con lo literario. Al respecto, Fernández Mallo declaró que sus textos "manejan un realismo complejo" (Mendoza, 2019, p. 261). De manera similar, ya Sergio Chejfec (2015) había sostenido que en los textos literarios hípercontemporáneos en donde los dispositivos y los medios digitales son parte de la vida cotidiana de los personajes se configura el verosímil digital de un nuevo realismo (p. 76).

\section{Referencias bibliográficas}

Bautista Botello, E., \& Pérez López, D. (2018). La Increíblemente Pequeña: Imágenes y escrituras digitales. En M. Alcántara, M. García Montero, \& F. Sánchez López (Eds.), Estudios culturales. Memoria del $56^{\circ}$ Congreso Internacional de Americanistas (pp. 588592). Ediciones Universidad de Salamanca.

Chejfec, S. (2015). Últimas noticias de la escritura. Entropía.

Choi, Y.-J. (2006). La literatura en el mundo virtual: Los escritores y el «blog» en América Latina. Espéculo. Revista de Estudios Literarios, XI (33 (julio-octubre)). http://webs.ucm. es/info/especulo/numero33/blogam.html

Choi, Y.-J. (2007). No hay tal lugar: La ciberliteratura de Cristina Rivera Garza. Espéculo. Revista de Estudios Literarios, XII (36 (julio-octubre)). https://webs.ucm.es/info/especulo/ numero36/cibliter.html

Choi, Y.-J. (2010). No hay tal lugar: La blogsívela de Cristina Rivera Garza. En O. Estrada (Ed.), Cristina Rivera Garza. Ningún crítico cuenta esto... (pp. 282-301). Eón.

crg. (2005, mayo 24). Esto no es un ataque personal contra el final. No hay tal lugar. http:// cristinariveragarza.blogspot.com/2005/05/

crg. (2007a, marzo 20). La inquietante (e internacional) semana de las mujeres traducidas. No hay tal lugar. http://cristinariveragarza.blogspot.com/2007/03/

crg. (2007b, julio 24). El fin del fin de la escritura/ II. No hay tal lugar. http://cristinariveragarza.blogspot.com/2007/07/ 
crg. (2011, noviembre 18). Escrituras transciberianas. No hay tal lugar. http://cristinariveragarza.blogspot.com/2011/11/

cristina. (2003, diciembre 29). Blogsívela 2003. LXXXXIII. Estertor. Words are the very eyes of secrecy. https://web.archive.org/web/20040107152315/http://cristinariveragarza. blogspot.com/2003_12_01_cristinariveragarza_archive.html

Cruz Arzabal, R. (2014, abril 18). Dispositivos artísticos post-digitales: Escrituras de ida y vuelta. Red de Humanidades Digitales. http://humanidadesdigitales.net/blog/2014/04/18/ dispositivos-artisticos-post-digitales-escrituras-de-ida-y-vuelta/

Cruz Arzabal, R. (2016). Archivos potenciales: Domiciliación y colindancias en Viriditas de Cristina Rivera Garza. Letras femeninas, 2(42), 35-43.

Cruz Arzabal, R. (Ed.). (2019). Aquí se esconde un paréntesis: Lecturas críticas a la obra de Cristina Rivera Garza. Universidad Nacional Autónoma de México.

Deleuze, G. (1983). L'Image-mouvement. Éd. de Minuit.

Estrada, O. (Ed.). (2010). Cristina Rivera Garza. Ningún crítico cuenta esto... Ediciones Eón-The University of North Carolina at Chapel Hill-UC Mexicanistas.

Federici, S. (2010). Calibán y la bruja. Mujeres, cuerpo y acumulación originaria (V. Hendel \& L. S. Touza, Trads.). Traficantes de Sueños.

Gallego Aguilar, A. F. (2011). Diseño de narrativas transmediáticas. Guía de referencia para las industrias creativas de paises emergentes en el contexto de la cibercultura. Universidad de Caldas.

Griboul, F. (2006). Ecriture errante. Navigation dans les blogs d'une écrivaine mexicaine: Cristina Rivera Garza. En M. Ezquerro (Ed.), Le texte et ses liens I. El texto y sus vínculos (pp. 143-156). Indigo \& Coté Femmes Editions.

Guerrero, G. (2018). Paisajes en movimiento. Literatura y cambio cultural entre dos siglos. Eterna Cadencia.

Hong, J.-E., \& Macías Rodríguez, C. (2007). Desde México para Corea. Entrevista a Cristina Rivera Garza. Espéculo. Revista de Estudios Literarios, XII (35). https://webs.ucm.es/info/ especulo/numero35/crisrive.html

Jenkins, H. (2003). Transmedia Storytelling. MIT Technology Review. http://www.technologyreview.com/news/401760/transmedia-storytelling/? $\mathrm{a}=\mathrm{f}$

Jenkins, H. (2006). Convergence culture. New York University Press.

Keizman, B. (2013). El blog de Cristina Rivera Garza: Experiencia literaria y terreno de contienda. Chasqui, 42(1), 3-5.

Keizman, B. (2020). Sensibilidades y rearticulaciones humanas y no humanas en la narrativa de Cristina Rivera Garza. Anclajes, XXIV (3), 189-203. https://doi.org/10.19137/ anclajes-2020-24312

Kinder, M. (1991). Playing with Power in Movies, Television, and Video Games: From Muppet Babies to Teenage Mutant Ninja Turtles. University of California Press.

Kozak, C. (2015). Transmedial. En C. Kozak (Ed.), Tecnopoéticas argentinas. Archivo blando de arte y tecnología (2, pp. 256-258). Caja Negra Editora.

Mendoza, J. J. (2019). Los archivos. Papeles para la nación. Eduvim.

Nallar, D. A. (2016). Diseño de juegos en América latina. Teoría y práctica. II. Diseño y narrativa transmedia. Game Design LA.

Olaizola, A. (2019). Las heroínas transmediales de Alba Cromm, de Vicente Luis Mora, y La 
muerte me da, de Cristina Rivera Garza. Cuaderno 91. Cuadernos del Centro de Estudios en Diseño y Comunicación, XXII (91), 65-78.

Olaizola, A. (2020). Las aventuras de la Increíblemente Pequeña: Trayectorias transmediales de una heroína errante. Cuadernos del Centro de Estudios en Diseño y Comunicación, 24(117), 85-102.

Palma Castro, A., Quintana, C., Lámbarry, A., Ramírez Olivares, A., \& Ríos Baeza, F. A. (Eds.). (2015). Cristina Rivera Garza: Una escritura impropia. Un estudio de su obra literaria (1991-2014). Ediciones EyC.

Papadopoulos, D., Stephenson, N., \& Tsianos, V. (2008). Escape Routes. Control and Subversion in the Twenty-first Century. Pluto Press.

Piglia, R. (1993). La Argentina en pedazos. Ediciones de la Urraca.

Porto, D., \& Flores, J. (2012). Periodismo transmedia: Reflexiones y estrategias de los medialabs en el desarrollo de la comunicación transmediática. Fragua Editorial.

Quintana, C. (2016). Cristina Rivera Garza. Une écriture-mouvement. Presses universitaires de Rennes.

Rivera Garza, C. (2004). Blogsívela. Escribir a inicios del siglo XXI desde la blogósfera. En Palabra de América (pp. 167-179). Seix Barral.

Rivera Garza, C. (2006). La escritura solamente. En M. Bellatin (Ed.), El arte de enseñar a escribir (pp. 78-82). Fondo de Cultura Económica, Escuela Dinámica de Escritores.

Rivera Garza, C. (2007). Introducción. Escribir un libro que no es mío. En C. Rivera Garza (Ed.), La novela según los novelistas (pp. 9-16). Fondo de Cultura Económica, Consejo Nacional para la Cultura y las Artes.

Rivera Garza, C. (2011a). El disco de Newton. Diez ensayos sobre el color. Bonobos Editores, UNAM.

Rivera Garza, C. (2011b). Viriditas. Mantis Editores y UANL.

Rivera Garza, C. (2013). Los muertos indóciles. Necroescrituras y desapropiación. Tusquets.

Rivera Garza, C. (2014). Los textos del yo ( $1^{\circ}$ edición electrónica). Fondo de Cultura Económica.

Rivera Garza, C. (2016). Breve historia íntima de la escritura en migración. Tierra Adentro. https://www.tierraadentro.cultura.gob.mx/breve-historia-intima-de-la-escritura-enmigracion/

Rivera Garza, C. (2019). Los muertos indóciles. Necroescrituras y desapropiación. Penguin Random House.

Rivera Garza, C. (2020). Autobiografía del algodón. Literatura Random House.

Ryan, M.-L. (2006). Avatars of Story. University of Minnesota Press.

Ryan, M.-L. (2007). Toward a Definition of Narrative. En D. Herman (Ed.), The Cambridge Companion to Narrative (pp. 22-35). Cambridge University Press.

Ryan, M.-L. (2008). Transfictionality Across Media. En J. Pier \& J. Á. García (Eds.), Theorizing Narrativity (pp. 385-417). De Gruyter.

Ryan, M.-L. (2013). Transmedial Storytelling and Transfictionality. Poetics Today, 34(3), 362-388. https://doi.org/10.1215/03335372-2325250

Ryan, M.-L. (2014). Story/Worlds/Media: Tuning the Instruments of a Media-Conscious Narratology. En M.-L. Ryan \& J.-N. Thon (Eds.), Storyworlds across Media: Toward a Media- Conscious Narratology (pp. 25-49). University of Nebraska Press. 
Ryan, M.-L. (2016). Transmedia Narratology and Transmedia Storytelling. Artnodes, 18. Ryan, M.-L. (2017). Transmedia Storytelling as Narrative Practice. En T. Leitch (Ed.), The Oxford Handbook of Adaptation Studies. Oxford University Press.

Saint-Gelais, R. (2005). Transfictionality. En M.-L. Ryan, D. Herman, \& M. Jahn (Eds.), The Routledge Encyclopedia of Narrative Theory (pp. 612-613). Routledge.

Sánchez-Aparicio, V. (2014). Y en el principio era Tlön: Transmedia de origen literario en las narrativas hispánicas. Caracteres: estudios culturales y críticos de la esfera digital. Monográfico: Universos transmedia y convergencias narrativas, 3(1), 61-80.

Sánchez-Aparicio, V. (2018). Respirar en el paisaje de los medios: Las poéticas disruptivas de Cristina Rivera Garza. Revista Landa, 7(1), 212-231.

Sánchez-Aparicio, V. (2019). Grietas textuales y discursos interrumpidos: El recurso del glitch en las «escrituras del software». Digithum, 23, 1-10. https://doi.org/10.7238/d. v0i23.3134

Schmitter, G. (2018). ¿Citar es escribir? Internet como plataforma creativa en la literatura argentina de lo ultracontemporáneo. Pandora, 14, 41-57.

Schmitter, G. (2019). Hacia unas TransLiteraturas hispanoamericanas: Reflexiones sobre literatura trans e intermedial en Argentina, Chile y Perú (2000-2017). La nueva novela latinoamericana sin límites. América sin nombre, 24, 53-62. https://doi.org/10.14198/ AMESN.2019.24-1.04

Scolari, C. A. (2008). Hipermediaciones. Elementos para una teoría de la Comunicación Digital Interactiva. Gedisa.

Scolari, C. A. (2009). Transmedia Storytelling: Implicit Consumers, Narrative Worlds, and Branding in Contemporary Media Production. International Journal of Communication, 3.

Scolari, C. A. (2013). Narrativas transmedia. Cuando todos los medios cuentan. Barcelona. Thon, J.-N. (2016). Transmedial Narratology and Contemporary Media Culture. University of Nebraska Press.

Tubau, D. (2011). El guion del siglo XXI. El futuro de la narrativa en el mundo digital. Alba. Wolfenzon, C. (2015, 2016). El novelista, sampleador del lenguaje. buensalvaje México, 2, 20-22.

Zipfel, F. (2014). Fiction across Media Toward a Transmedial Concept of Fictionality. En M.-L. Ryan \& J.-N. Thon (Eds.), Storyworlds across Media Toward a Media- Conscious Narratology (pp. 103-125). University of Nebraska Press.

\section{Writing in migration: transmediality and poetics in Cristina Rivera Garza}

Abstract: In articles included in two previous volumes (El camino de la heroína, el arquetipo femenino universal para un nuevo paradigma and El camino de la heroína, narrativa, género y diversidad) we have advanced in the identification of transmedia strategies in a corpus of texts by the Mexican writer Cristina Rivera Garza.

This article continues with this research line and deepens it, to reflect on how transmediality is part of Rivera Garza's poetics, or rather, how transmedial drifts execute, but at the 
same time make possible, the trajectories through the genres, media and languages that the Mexican writer postulates in printed and digital essays that develop her aesthetic and poetic approaches.

Rivera Garza herself has defined her writing as in constant suspense, irresolute between genres. For the Mexican writer, writing is a practice, a work with language in and from movement: when writing, the physiological is transformed, the psychological is transformed. "Writing is the physical act of thinking" (Rivera Garza, 2007, p. 13): the body and mind in motion in and through writing, which reproduces that same wandering, that becoming in and through languages, texts, genres and media.

Keywords: Transmediality - Transfictionality - Writing in migration - Digital writing Adjoining writings - Blogs - Poetics - Rivera Garza - Latin American literature of the XXI century - Mexican literature of the XXI century.

\section{Escrita em migração: o transmídia na poética de Cristina Rivera Garza}

Resumo Em artigos incluídos em dois volumes anteriores (El camino de la heroína, el arquetipo femenino universal para un nuevo paradigma e El camino de la heroína, narrativa, género y diversidad) avançamos na identificação de estratégias transmídia em um corpus de textos da escritora mexicana Cristina Rivera Garza.

Este artigo dá continuidade a esse eixo de pesquisa e o aprofunda, para refletir sobre como a transmidialidade faz parte da poética de Rivera Garza, ou melhor, como as derivas transmídia executam, mas ao mesmo tempo possibilitam, as trajetórias pelos gêneros, mídias e linguagens que a escritora mexicana postula nos textos de ensaios impressos e digitais que desenvolvem suas abordagens estéticas e poéticas.

A própria Rivera Garza definiu sua escrita como um suspense constante, indecisa entre os gêneros. Para o escritor mexicano, a escrita é uma prática, um trabalho com a linguagem no e a partir do movimento: ao escrever, o fisiológico se transforma, o psicológico se transforma. "Escrever é o ato físico de pensar" (Rivera Garza, 2007, p. 13): o corpo e a mente em movimento na e pela escrita, que reproduz essa mesma errância, aquele devir em e por meio de linguagens, textos, gêneros e mídias.

Palavras-chave: Transmedialidade - Transficcionalidade - Escrita em migração - Escrita digital - Escrita contígua - Blogs - Poética - Rivera Garza - Literatura latino-americana do século XXI - Literatura mexicana do século XXI Transmedialidad - Transficcionalidad Escritura en migración - Escrituras digitales - Escrituras colindantes - Blogs - Poéticas - Rivera Garza - Literatura latinoamericana del siglo XXI - Literatura mexicana del siglo XXI.

[Las traducciones de los abstracts fueron supervisadas por el autor de cada artículo] 